Article

\title{
Improving Knowledge about the Sustainable Development Goals through a Collaborative Learning Methodology and Serious Game
}

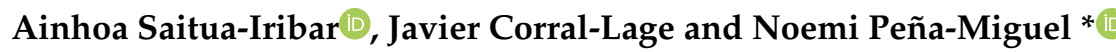 \\ Financial Economics I, University of the Basque Country (UPV/EHU), 48015 Bilbao, Spain; \\ ainhoa.saitua@ehu.eus (A.S.-I.); javier.corral@ehu.eus (J.C.-L.) \\ * Correspondence: noemi.pena@ehu.eus
}

Received: 1 July 2020; Accepted: 29 July 2020; Published: 31 July 2020

check for updates

\begin{abstract}
The university is a key agent in the process of transformation towards sustainability within the framework of the 2030 Agenda. This study aims to analyze the usefulness of the collaborative learning methodology through a serious game (SG) in the university environment to increase the level of knowledge and the importance given to the Sustainable Development Goals (SDGs) by students. Through ex ante and ex post questionnaires, the degree of variation in the knowledge acquired and importance given to the SDGs was measured. To compare the midrange of these two samples and determine whether differences existed, we applied the Student and Wilcoxon $t$-tests. The results indicate that the methodology used produced an improvement in knowledge about the SDGs. Therefore, it is concluded that the university should promote this type of workshop and SG activities to contribute to the achievement of the SDGs, both in the Bachelor's Degree in Primary Education and in degrees of other disciplines. Moreover, we have encouraged active learning of the SDGs through collaborative workshops using the design thinking method and an SG called "The Island", which, based on certain economic, social and environmental information, puts students in a position to govern resources to meet the needs of its population.
\end{abstract}

Keywords: UN 2030 Agenda; higher education; sustainability; serious games; SDG; collaborative learning

\section{Introduction}

The United Nations (UN), through the 2030 Agenda, poses global challenges that, along with an economic vision, include social and environmental perspectives [1]. This agenda, which is based on the 17 Sustainable Development Goals (SDGs), includes the actions to be developed in the coming years by public administrations, private companies, nonprofit organizations, universities and the general public. The aim of the 17 objectives, with their 169 targets, is to guarantee a sustainable, peaceful, fair and prosperous life for all the inhabitants of our planet now and in the future. They set environmental limits and align poverty eradication actions with economic development strategies without forgetting social needs and climate change [2]. The SDGs cover a set of interconnected themes that challenge society, such as health, education, climate action, peace and strong institutions [3].

Society has begun to value and demand greater involvement from companies, public administrations and educational institutions as agents that serve and affect the social and economic environment [4]. Thus, in the application of European Directive 2014/95/EU in Spain, Law 11/2018 [5] obliges certain large companies to report on the SDG commitments acquired by the entity in the nonfinancial information statement within the management report they publish, together with the annual accounts (balance sheet, profit and loss account, etc.) or in a separate report. 
By showing their commitment to the SDGs, entities can enter into a "war for talent", as the people to be hired may be more attracted to more sustainable companies [3].

In this context, it is necessary to better train future professionals who are going to work in companies, whether they are obliged to report economic, social and environmental information or do so voluntarily, or in entities that make up interest groups in these companies and use this type of information, as well as in other types of entities (public entities and educational centers, among others) committed to the 2030 Agenda. Therefore, we must prepare university students so that they can help companies and other entities face these challenges. Specifically, students (future professionals who will work in different companies or entities) should be able to carry out five phases: (1) understand the SDGs and what the responsibilities of the companies are; (2) define priorities; (3) establish objectives; (4) integrate them into the management of the entity; and (5) report (communicate) the results obtained, both in economic, social and environmental terms [3].

Specifically, the university, as a key agent in the process of transformation towards sustainability, must commit itself to promoting sustainable values in the student body [6,7]. Education must promote equity and respect and help students understand the situation, perspectives and needs of people living in other parts of the world or belonging to another generation [8]. Teaching about sustainable development seeks to confront students with ethical issues in which they must decide what standards and codes society should develop in order to frame human actions that seek greater economic well-being while sustaining the natural environment [9]. Thus, students will have to assess and develop a code of ethics for sustainability when deciding which resources to use for economic, social and environmental challenges, both in the classroom and in real life [9].

Miller [10] established a hierarchy of competency levels for the medical profession (knowing how, demonstrating and doing), which is easily transferable to other professions [7]. In the field of university education, the integration of the European Higher Education Area advocates teaching methodologies that help students develop their skills in an active and meaningful way.

Methodologies associated with innovation must be an inexorable part of daily educational practice and must be supported by the use of educational and technological resources available [11]. In this context, the use of games as learning tools seems to be a promising approach due to their ability to teach and reinforce not only knowledge but also skills such as problem solving, collaboration or communication [9,12]. According to the Young Business Talents Report, games help increase the level of passing [13], so we understand that it also improves the degree of knowledge of the subjects in question.

The use of technological tools and innovative approaches allows students to understand abstract concepts [14]. However, technological resources such as serious games (SGs), created to promote sustainable education [15-18], are practically nonexistent as teaching tools, which is inconsistent with the development of both pedagogical concepts, information and communication technologies (ICTs), the games themselves and the skills and characteristics of the students [19]. Moreover, there are hardly any studies that match these two subjects, SGs and the SDGs, in a collaborative learning approach. This study contributes to this endeavor.

Nonetheless, the results of studies related to the effectiveness of SGs in terms of sustainability are inconclusive. On the one hand, Ouriachi, Overa-Lobo and Gutiérrez-Pérez [17] did not find statistically significant differences after the use of an SG. On the other hand, Rojo and Dudu [18] showed that SGs had an individualistic profile and were limited when working in different areas related to sustainability. However, Katsaliaki and Musafee [15] concluded that these games increased players' understanding of events around sustainability and strengthened their knowledge of sustainable development strategies. Furthermore, to introduce ideas on sustainable development, Prado et al. [9] found that simulations were more effective than case studies, especially in terms of multidimensionality and intertemporality. In this sense, high-level programming software can solve real-life problems, such as the correct design of water supply tanks, the overall planning of a given area or the estimation of water availability in various climate change scenarios [20]. 
The inclusion in the university curriculum of the promotion of sustainable development (sustainable curriculum), the implementation of active methodologies in the classroom and the use of ICTs, such as business simulators or SGs, are essential to improving the necessary theoretical and practical knowledge to promote sustainable development [21-23].

In our case, based on the social need to manage or administer companies and other types of entities, both private and public, we take as our first general reference SDG 17 (revitalize alliances) to achieve SDG 16 (peaceful societies), and this is done through SDG 10 (reduce inequalities) by means of SDG 12 (ensure responsible production and consumption) and SDG 8 (sustained economic growth with decent work).

Therefore, the aim of this study is to analyze the effect of a learning experience based on a collaborative workshop and the use of an SG in the university environment to increase the level of knowledge and the importance given to the SDGs. This experience is in relation to training on Education for Sustainable Development (ESD) and based on the triple economic, social and environmental perspective. To this end, the following research questions (RQs) are posed:

RQa: Is the learning experience (collaborative workshop including a decision-making simulation game) useful for increasing the level of knowledge about the SDGs?

$\mathrm{RQb}$ : Is the learning experience (collaborative workshop that includes a decision-making simulation game) useful for increasing the level of importance placed on the SDGs?

\section{Methods}

The learning experience described here was part of a project within the framework of the CBL (Campus Bizia Lab) initiative of the University of the Basque Country (UPV/EHU), which has as one of its objectives to foster collaboration between administration and service staff, teachers and students. In the style of other universities [24], the ultimate purpose of this initiative is to investigate and raise awareness about sustainability and even solve real problems at the university.

As far as we know, the effect of this type of educational intervention of workshops with design thinking methodology and the use of an SG for undergraduate students in primary education has not yet been investigated.

\subsection{Collaborative Workshops and SG}

The learning experience began with collaborative workshops in which we have encouraged the active learning of the SDGs using the design thinking method, which incorporates elements of the research method studied by Caamaño [25]. An SG called "The Island", which, based on certain economic, social and environmental information, puts students in a position to manage resources (create or destroy homes, industries, etc.) to meet the needs of its population, was used.

The initial workshop, based on active methodologies, took place in a three-hour session. Students were required to bring one laptop for each group of three people. The first activity, called Lotus Blossom, consisted of dividing the large group into small groups of five people to identify the actions related to sustainability that they were developing in the area of academic teaching that they were studying or in the area of management in their school (building conditions, etc.) as well as the actions that they believed should be carried out. Each group was to focus on one of eight areas, write it down on a Post-it Note and then explain it in the general group. The eight areas were as follows: (i) Current Economic, (ii) Future Economic, (iii) Current Environmental, (iv) Future Environmental, (v) Current Social, (vi) Future Social, (vii) Current Political and (viii) Future Political. The result of the debate was that, according to the perception of the students in the degree of education, for example, in the current economic field, no action was being taken in their education, and measures should be implemented to make them aware of the functioning of the world economy.

For the second activity, called Orange and Green Cards, the students were divided into 16 groups (the groups from the previous activity were subdivided into two). SDG 17 was explained by the research faculty who organized the activity. Afterwards, each group had to look for information about 
the SDG assigned to them and propose an improvement from their perspective as students in the primary education grade. When a group made a proposal or explained something, the rest of the teams would raise the green card if they had understood it well and agreed or the orange card if they needed something clarified or did not agree.

Finally, the last activity took place over three hours and consisted of playing the SG called "The Island". This SG involves five cities over which eight seasons pass (summer, winter, etc.), and players play (make different decisions) in each of them before moving on to the next one. Data on the weather of each location (more or less sunshine, more or less wind, etc.) is provided so that the effectiveness of the different energy stations (solar, etc.) can be calculated. With an initial budget, participating groups in the game can decide by consensus whether to build more houses and can choose from several types that have different energy efficiency characteristics. They can plant crops, choosing the area most suitable for them, build different types of industries, etc. When they move from one season to another, they can find out what the impact is in terms of the environmental field (as soon as the pollution has increased or decreased) and the citizens' assessment (less or more than in the previous season) once the corresponding decisions have been taken.

The economic, environmental (climate, soil) and social (energy infrastructure, housing, transport, jobs, etc.) aspects are taken into account. Therefore, the game covers almost all SDGs. In the first round, one-third of the groups made their decisions solely on the basis of economic criteria, one-third on the basis of social criteria and one-third on the basis of environmental criteria. Once the round was over, they shared the decisions they had made and the results achieved (variation in the budget, the level of environmental pollution and citizen satisfaction), and in the following rounds, once the previous knowledge had been acquired, they considered all the criteria at the same time.

Unlike the software used by González-Alriols et al. [20], the software we used is suitable for people who do not have specific technical knowledge of the different decision areas (types of housing or types of wind, thermal, nuclear power plants, etc.), and it facilitates a description of the main functional characteristics (more or less polluting, etc.) and cost of each option.

\subsection{Data Collection Instruments}

This was an exploratory work based on the quantitative paradigm. To that end, a five-point Likert scale survey was used. Through two questionnaires, information was collected in order to analyze if there were differences in perception regarding the knowledge of each of the 17 SDGs before and after the use of the SG to assess whether there was an improvement in the knowledge acquired about the SDGs by the analyzed group, as well as in the importance that this collective granted to each of the 17 SDGs.

\subsection{Participants. Sample for the Analysis}

Mulà et al. [26] underlined the importance of university professors who are trained in sustainability in the first place. To carry out this study, we have taken a sample of convenience, consisting of the first-year group of the natural sciences, a subject of the primary education degree in the UPV/EHU in Leioa (Bizkaia, Spain) in which some sustainability concepts are already being studied. The activity was carried out in the second semester of the 2018/2019 academic year.

In our case, focusing on SDG 4, quality education, we have taken as a sample of analysis university students who will subsequently be education professionals. Thus, we understood that the students of the degree in education as a subject of study were of interest for two reasons. First, the opinions of this sample could be considered a proxy or indicator of the opinions of society in general, to the extent that students have not had to complete a specific baccalaureate (science, social science or the arts), being capable of taking any of the modalities. On the other hand, knowing the perceptions of this group was of great interest, to the extent that these people are the ones who are going to train the primary school students of the future generations of our society, a group that must also be trained in sustainability in order to influence the sustainable values $[2,7,27,28]$. 
As a first approximation of the students who have participated in the educational intervention, and in the application of the agreement of the Governing Council of the University of the Basque Country of 2 November 2017 regarding the application of a third box in application or survey forms [29], the survey included the "nonbinary" option on gender. In this case, none of the people identified in the "nonbinary" category. On the other hand, according to the high socialization in the traditional gender values that result in a greater feminization of primary education studies [30], of the 47 participants, only 10 were men; the majority $(78.7 \%)$ were women. On the other hand, before carrying out the activity of workshops and SGs, almost half responded that they had not received sustainability training in any subject (42.6\%), although the rest $(57.4 \%)$ considered that they had received some training in one, two or more subjects. When asked if they had thought about choosing a theme related to sustainability for their final degree project, eight people (17\%) responded that they would not, but most $(80.9 \%)$ did not know or did not answer, since they were still in the first year. Finally, the majority of students (93.6\%) said they had never used a simulator or business game in their university life. This is also logical, since their university life was still limited to the first year of the degree (Table 1).

Table 1. Participants by gender, by number of subjects in which they have received sustainability training, by intention to choose sustainability for their end of degree project and by the number of subjects in which they have used a simulator or business game.

\begin{tabular}{ccc}
\hline Gender & Frequency & Percentage \\
\hline WOMAN & 37 & 78.7 \\
MAN & 10 & 21.3 \\
Total & 47 & 100.0 \\
\hline Have received sustainability training in one or & Frequency & Percentage \\
more subjects & 20 & 42.6 \\
\hline subjects & 19 & 40.4 \\
1 subject & 7 & 14.9 \\
2 subjects & 1 & 2.1 \\
$>3$ subjects & 47 & 100.0 \\
Total & & \\
\hline Plan to choose a topic related to sustainability & Frequency & Percentage \\
for their end of degree project & 8 & 17.0 \\
NO & 38 & 80.9 \\
Do not know/no answer & 1 & 2.1 \\
YES & 47 & 100.0 \\
Total & Frequency & Percentage \\
\hline Tubjects who have used an SG in their & 44 & 93.6 \\
academic life & 3 & 6.4 \\
\hline 0 subjects & 47 & 100.0 \\
\hline subject & &
\end{tabular}

\section{Results}

First, whether the different ex ante and ex post samples followed a normal distribution was determined through the Shapiro-Wilk statistical test. To compare the average range of these two samples and determine if there were differences, we applied Student's $t$-test for the samples that met the normality and applied the Wilcoxon criteria for those that did not.

When testing the significance of the issues investigated, we first needed to determine whether each of the variables (x) of "knowledge degree" (KD) and "importance degree" (ID) granted for each of the SDGs had a normal distribution before (_PRE) and after (_POST) the activity. 
H0: The variable $(x)$ in the population has a normal distribution.

H1: The variable $(x)$ in the population is different from the normal distribution.

In this case, since the sample size was less than 50 observations, we used the Shapiro-Wilk test (Tables 2 and 3). Thus, the null hypothesis $(p=0.00<0.05)$ was rejected in the sense that there were no differences; that is, they did not meet normality in most cases ("knowledge degree" and "importance degree" relative to each of the SDGs individually, before and after the activity, as well as for the means corresponding to the importance attached to the SDGs together, before and after). Only the means of the knowledge degree of the SDGs, both before (KD_SDG_MEDIA_PRE, $p=0.721>0.05)$ and after the innovative activity (KD_SDG_MEDIA_POST, $p=0.931>0.05)$ (Table 2), were Gaussian samples, which meet normality.

Table 2. Normality tests for the different related samples—-knowledge level.

\begin{tabular}{ccccc}
\hline Normality Tests & Shapiro-Wilk Test & Sig. & Normality Tests & Shapiro-Wilk Test \\
\hline KD_SDG 1_PRE & 0.857 & 0.000 & KD_SDG 1_POST & 0.882 \\
KD_SDG 2_PRE & 0.858 & 0.000 & KD_SDG 2_POST & 0.887 \\
KD_SDG 3_PRE & 0.860 & 0.000 & KD_SDG 3_POST & 0.843 \\
KD_SDG 4_PRE & 0.865 & 0.000 & KD_SDG 4_POST & 0.891 \\
KD_SDG 5_PRE & 0.858 & 0.000 & KD_SDG 5_POST & 0.858 \\
KD_SDG 6_PRE & 0.856 & 0.000 & KD_SDG 6_POST & 0.891 \\
KD_SDG 7_PRE & 0.904 & 0.001 & KD_SDG 7_POST & 0.880 \\
KD_SDG 8_PRE & 0.875 & 0.000 & KD_SDG 8_POST & 0.875 \\
KD_SDG 9_PRE & 0.827 & 0.000 & KD_SDG 9_POST & 0.799 \\
KD_SDG 10_PRE & 0.889 & 0.000 & KD_SDG 10_POST & 0.889 \\
KD_SDG 11_PRE & 0.866 & 0.000 & KD_SDG 11_POST & 0.013 \\
KD_SDG 12_PRE & 0.909 & 0.001 & KD_SDG 12_POST & 0.000 \\
KD_SDG 13_PRE & 0.886 & 0.000 & KD_SDG 13_POST & 0.000 \\
KD_SDG 14_PRE & 0.844 & 0.000 & KD_SDG 14_POST & 0.000 \\
KD_SDG 15_PRE & 0.877 & 0.000 & KD_SDG 15_POST & 0.000 \\
KD_SDG 16_PRE & 0.912 & 0.002 & KD_SDG 16_POST & 0.000 \\
KD_SDG 17_PRE & 0.800 & 0.000 & KD_SDG 17_POST & 0.000 \\
KD_SDG_MEDIA_PRE & 0.983 & 0.721 & KD_SDG_MEDIA_POST & 0.001 \\
\hline
\end{tabular}

Table 3. Normality tests for the different related samples-importance level.

\begin{tabular}{lccccc}
\hline Normality Tests & Shapiro-Wilk Test & Sig. & Normality Tests & Shapiro-Wilk Test & Sig. \\
\hline ID_SDG 1_PRE & 0.580 & 0.000 & ID_SDG 1_POST & 0.623 & 0.000 \\
ID_SDG 2_PRE & 0.500 & 0.000 & ID_SDG 2_POST & 0.621 & 0.000 \\
ID_SDG 3_PRE & 0.595 & 0.000 & ID_SDG 3_POST & 0.638 & 0.000 \\
ID_SDG 4_PRE & 0.580 & 0.000 & ID_SDG 4_POST & 0.525 & 0.000 \\
ID_SDG 5_PRE & 0.397 & 0.000 & ID_SDG 5_POST & 0.608 & 0.000 \\
ID_SDG 6_PRE & 0.601 & 0.000 & ID_SDG 6_POST & 0.676 & 0.000 \\
ID_SDG 7_PRE & 0.675 & 0.000 & ID_SDG 7_POST & 0.679 & 0.000 \\
ID_SDG 8_PRE & 0.736 & 0.000 & ID_SDG 8_POST & 0.615 & 0.000 \\
ID_SDG 9_PRE & 0.804 & 0.000 & ID_SDG 9_POST & 0.732 & 0.000 \\
ID_SDG 10_PRE & 0.621 & 0.000 & ID_SDG 10_POST & 0.652 & 0.000 \\
ID_SDG 11_PRE & 0.687 & 0.000 & ID_SDG 11_POST & 0.688 & 0.000 \\
ID_SDG 12_PRE & 0.719 & 0.000 & ID_SDG 12_POST & 0.711 & 0.000 \\
ID_SDG 13_PRE & 0.642 & 0.000 & ID_SDG 13_POST & 0.692 & 0.000 \\
ID_SDG 14_PRE & 0.721 & 0.000 & ID_SDG 14_POST & 0.736 & 0.000 \\
ID_SDG 15_PRE & 0.778 & 0.000 & ID_SDG 15_POST & 0.665 & 0.000 \\
ID_SDG 16_PRE & 0.623 & 0.000 & ID_SDG 16_POST & 0.662 & 0.000 \\
ID_SDG 17_PRE & 0.785 & 0.000 & ID_SDG 17_POST & 0.772 & 0.000 \\
ID_SDG_MEDIA_PRE & 0.838 & 0.000 & ID_SDG_MEDIA_POST & 0.809 \\
\hline
\end{tabular}

This first analysis regarded the first research question:

RQa: Is the learning experience useful for increasing the level of knowledge about the SDGs?

In the first place, we performed the statistical tests necessary to determine if there was a significant difference between the means of the two groups (ex ante and ex post). We proposed as the first hypotheses: 
H0_a: The methodological initiative that includes an SG does not affect the knowledge of the SDGs.

H1_a: The methodological initiative that includes an SG does affect the knowledge of the SDGs.

As we have seen, the statistical tests applied in order to determine the significance needed to be different. For samples that met normality (the average of the degree of knowledge of the SDGs, before and after the innovative activity), we used Student's $t$. Thus, we applied Student's $t$ to corroborate if the SG significantly affected the average level of knowledge, that is, in general, of the SDGs (Table 4). The value obtained was $p=0<0.05$, so we rejected H0. That is to say, there was a difference between the average of the degree of knowledge before and after the activity; therefore, based on Student's t-distribution (3.998), we could confirm that the use of the SG positively affected the degree of knowledge mean (general) about the SDGs.

Table 4. Significance tests for samples with normal distribution.

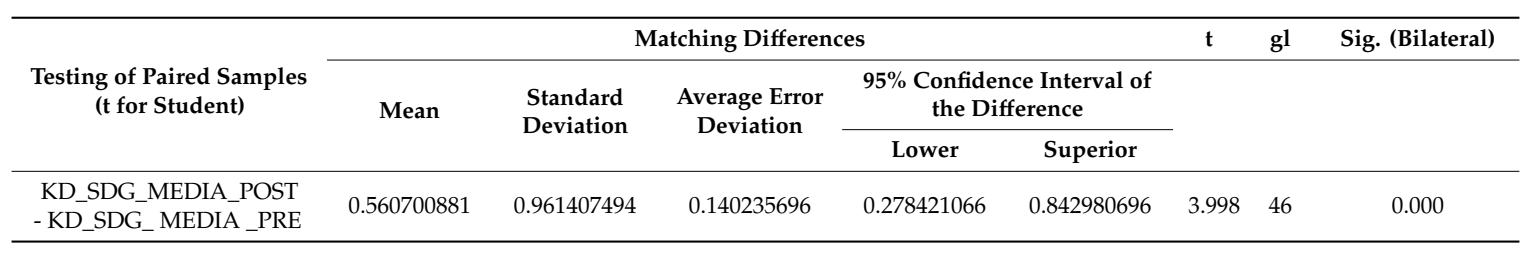

On the other hand, for the samples that did not meet the norm (KD and ID of each of the SDG individually, before and after the activity, as well as the means related to the importance given to the SDGs before and after), we used the Wilcoxon test (Table 5).

Thus, 11 of the SDGs were affected by the SG: 1 (ending poverty), 2 (zero hunger), 6 (clean water and sanitation), 7 (affordable and clean energy), 8 (decent work and economic growth), 9 (industry, innovation and infrastructure), 11 (sustainable cities and communities), 12 (responsible production and consumption), 14 (underwater life), 15 (life of terrestrial ecosystems) and 17 (partnerships to achieve the goals).

However, the SG did not affect the level of knowledge of six of the SDGs: 3 (health and welfare), 4 (quality education), 5 (gender equality), 10 (reducing inequalities), 13 (climate action) and 16 (peace, justice and strong institutions). This is logical because the SG did not incorporate data from individual people but from the general population. Thus, it did not take into account the gender of individuals (SDG 5), nor did it take into account inequalities between individuals (SDG 10), aspects of individual people's health (SDG 3) or the educational level of each individual (SDG 4). However, the SG did involve making decisions regarding the creation of crops (SDG 2), industries (SDGs 1 and 8), the choice of types of power plants according to their level of pollution (SDGs 6, 7, 14 and 15) and transport infrastructure (SGDs 9 and 11).

Therefore, even though the SG has some limitations because it cannot ensure the increase of knowledge about each and every SDG, we can affirm that it contributed to the significant improvement of $64.7 \%$ of the SDGs.

As for the second question:

$\mathrm{RQb}$ : Is the learning experience useful for increasing the level of importance that students attach to the SDGs?

We proposed the following hypotheses:

H0_b: The methodological initiative that includes an SG does not affect the level of importance given to the SDGs.

H1_b: The methodological initiative that includes an SG does affect the level of importance given to the SDGs.

In this case, based on the statistical evidence, there was no evidence that the degree of importance was affected by the educational intervention using an SG (Table 5), neither by analyzing the means (Table 6) nor by analyzing each SDG individually (values $>0.05$ ). 
Table 5. Significance tests for samples with non-normal distribution in relation to the level of knowledge about the Sustainable Development Goals (SDGs) individually.

\begin{tabular}{|c|c|c|c|c|c|}
\hline $\begin{array}{c}\text { Testing of Paired } \\
\text { Samples (Wilcoxon) }\end{array}$ & Z & $\begin{array}{c}\text { Sig. } \\
\text { Asymptotics } \\
\text { (Bilateral) }\end{array}$ & $\begin{array}{c}\text { Testing of Paired } \\
\text { Samples (Wilcoxon) }\end{array}$ & Z & $\begin{array}{c}\text { Sig. } \\
\text { Asymptotics } \\
\text { (Bilateral) }\end{array}$ \\
\hline $\begin{array}{l}\text { KD_SDG 1_POST - } \\
\text { KD_SDG 1_PRE }\end{array}$ & $-2.537^{\mathrm{a}}$ & 0.011 * & $\begin{array}{l}\text { ID_SDG 1_POST - } \\
\text { ID_SDG 1_PRE }\end{array}$ & $-0.406^{a}$ & 0.685 \\
\hline $\begin{array}{l}\text { KD_SDG 2_POST - } \\
\text { KD_SDG 2_PRE }\end{array}$ & $-2.897^{\mathrm{a}}$ & 0.004 * & $\begin{array}{l}\text { ID_SDG 2_POST - } \\
\text { ID_SDG 2_PRE }\end{array}$ & $-1.334^{\mathrm{a}}$ & 0.182 \\
\hline $\begin{array}{l}\text { KD_SDG 3_POST - } \\
\text { KD_SDG 3_PRE }\end{array}$ & $-1.492^{\mathrm{a}}$ & 0.136 & $\begin{array}{l}\text { ID_SDG 3_POST - } \\
\text { ID_SDG 3_PRE }\end{array}$ & $-0.617^{\mathrm{a}}$ & 0.537 \\
\hline $\begin{array}{l}\text { KD_SDG 4_POST - } \\
\text { KD_SDG 4_PRE }\end{array}$ & $-1.093^{b}$ & 0.275 & $\begin{array}{l}\text { ID_SDG 4_POST - } \\
\text { ID_SDG 4_PRE }\end{array}$ & $-0.832^{b}$ & 0.405 \\
\hline $\begin{array}{l}\text { KD_SDG 5_POST - } \\
\text { KD_SDG 5_PRE }\end{array}$ & $-0.718^{a}$ & 0.473 & $\begin{array}{l}\text { ID_SDG 5_POST - } \\
\text { ID_SDG 5_PRE }\end{array}$ & $-1.762^{a}$ & 0.078 \\
\hline $\begin{array}{l}\text { KD_SDG 6_POST - } \\
\text { KD_SDG 6_PRE }\end{array}$ & $-3.402^{a}$ & 0.001 * & $\begin{array}{l}\text { ID_SDG 6_POST - } \\
\text { ID_SDG 6_PRE }\end{array}$ & $-1.208^{a}$ & 0.227 \\
\hline $\begin{array}{l}\text { KD_SDG 7_POST - } \\
\text { KD_SDG 7_PRE }\end{array}$ & $-3.378^{a}$ & 0.001 * & $\begin{array}{l}\text { ID_SDG 7_POST - } \\
\text { ID_SDG 7_PRE }\end{array}$ & $-0.171^{b}$ & 0.864 \\
\hline $\begin{array}{l}\text { KD_SDG 8_POST - } \\
\text { KD_SDG 8_PRE }\end{array}$ & $-4.010^{\mathrm{a}}$ & $0.000 *$ & $\begin{array}{l}\text { ID_SDG 8_POST - } \\
\text { ID_SDG 8_PRE }\end{array}$ & $-0.687^{b}$ & 0.492 \\
\hline $\begin{array}{l}\text { KD_SDG 9_POST - } \\
\text { KD_SDG 9_PRE }\end{array}$ & $-4.394^{\mathrm{a}}$ & $0.000 *$ & $\begin{array}{l}\text { ID_SDG 9_POST - } \\
\text { ID_SDG 9_PRE }\end{array}$ & $-1.226^{b}$ & 0.220 \\
\hline $\begin{array}{l}\text { KD_SDG 10_POST - } \\
\text { KD_SDG 10_PRE }\end{array}$ & $-0.328^{a}$ & 0.743 & $\begin{array}{l}\text { ID_SDG 10_POST - } \\
\text { ID_SDG 10_PRE }\end{array}$ & $-1.390^{a}$ & 0.165 \\
\hline $\begin{array}{l}\text { KD_SDG 11_POST - } \\
\text { KD_SDG 11_PRE }\end{array}$ & $-4.477^{\mathrm{a}}$ & $0.000 *$ & $\begin{array}{l}\text { ID_SDG 11_POST - } \\
\text { ID_SDG 11_PRE }\end{array}$ & $-0.253^{b}$ & 0.800 \\
\hline $\begin{array}{l}\text { KD_SDG 12_POST - } \\
\text { KD_SDG 12_PRE }\end{array}$ & $-2.048^{a}$ & 0.041 * & $\begin{array}{l}\text { ID_SDG 12_POST - } \\
\text { ID_SDG 12_PRE }\end{array}$ & $-0.251^{b}$ & 0.802 \\
\hline $\begin{array}{l}\text { KD_SDG 13_POST - } \\
\text { KD_SDG 13_PRE }\end{array}$ & $-1.120^{a}$ & 0.263 & $\begin{array}{l}\text { ID_SDG 13_POST - } \\
\text { ID_SDG 13_PRE }\end{array}$ & $-0.646^{a}$ & 0.518 \\
\hline $\begin{array}{l}\text { KD_SDG 14_POST - } \\
\text { KD_SDG 14_PRE }\end{array}$ & $-3.438^{a}$ & $0.001 *$ & $\begin{array}{l}\text { ID_SDG 14_POST - } \\
\text { ID_SDG 14_PRE }\end{array}$ & $-0.138^{b}$ & 0.890 \\
\hline $\begin{array}{l}\text { KD_SDG 15_POST - } \\
\text { KD_SDG 15_PRE }\end{array}$ & $-2.569^{a}$ & $0.010 *$ & $\begin{array}{l}\text { ID_SDG 15_POST - } \\
\text { ID_SDG 15_PRE }\end{array}$ & $-1.522^{b}$ & 0.128 \\
\hline $\begin{array}{l}\text { KD_SDG 16_POST - } \\
\text { KD_SDG 16_PRE }\end{array}$ & $-1.903^{a}$ & 0.057 & $\begin{array}{l}\text { ID_SDG 16_POST - } \\
\text { ID_SDG 16_PRE }\end{array}$ & $-0.688^{a}$ & 0.491 \\
\hline $\begin{array}{l}\text { KD_SDG 17_POST - } \\
\text { KD_SDG 17_PRE }\end{array}$ & $-3.982^{a}$ & $0.000 *$ & $\begin{array}{l}\text { ID_SDG 17_POST - } \\
\text { ID_SDG 17_PRE }\end{array}$ & $-0.219^{b}$ & 0.827 \\
\hline
\end{tabular}

${ }^{a}$ based on negative ranges; ${ }^{b}$ based on positive ranges; ${ }^{*}$ less than 0.05 .

Table 6. Significance tests for samples with non-normal distribution in relation to the mean of the degree of importance attached to the SDGs.

\begin{tabular}{ccc}
\hline Range Testing Signed by Wilcoxon & Z & Sig. Asymptotics (Bilateral) \\
\hline ID_SDG_MEDIA_POST - ID_SDG_MEDIA_PRE & $-0.051^{\text {a }}$ & 0.959 \\
\hline
\end{tabular}

Therefore, based on the averages in general, we concluded that the SG did not affect the degree of importance that the students attached to the SDGs but affected the degree of knowledge about them, so it was useful for sustainability education.

\section{Discussion}

According to Canals et al. [31], bringing science (in the case of their article, environmental) closer to the general public and to young people is a challenge for the scientific community. The combination of active learning practices that combine the acquisition of knowledge, the development of self-management skills and responsibility can bear good fruit. Similar to their work, which sought to awaken the interest of participating students in the ecological and environmental science field, to convey this group to the rest of the students and, finally, to examine it with the teaching staff involved in this educational problem, our teaching and learning experience also had the objective of promoting knowledge about the SDGs to participating students. 
In line with the results of Katsaliaki et al. [15] and Prado et al. [9], the use of the SG did contribute to the improvement of knowledge about the SDGs. In relation to the averages of the degree of knowledge (KD_MEDIA) and degree of importance (ID_MEDIA) of both the ex ante and the ex post, the fact that the use of an SG only affected the degree of knowledge implies that this may be logical due to the fact that the students have been able to receive certain training on sustainability in preuniversity education, and we even know that they have done so in the very subject in which we have carried out the intervention, so the students would already be aware of its importance.

Furthermore, in line with the idea of the "drop of water effect" that permeates the university and society $[7,32]$, we believe that the transmission of knowledge generated through the methodological process described in this research produces an indirect contribution, both through the communication that participating students can have with nonparticipating students with whom they relate throughout the university degree and through the training of the rest of the teaching staff that has helped carry out this activity.

\section{Conclusions}

This article aimed to analyze the usefulness of a collaborative learning methodology through SGs in the university environment to increase the level of knowledge and the importance given to the Sustainable Development Goals (SDGs) by students.

It has been demonstrated that the use of SGs affected the degree of knowledge of SDGs. However, educational intervention with simulation games did not affect the degree of importance that students gave them. Therefore, this SG used in a collaborative way after a learning process based on the design thinking methodology provided users with a greater knowledge of the SDGs, which were worked on in a nonindividual way and allowed the development of creativity, critical attitudes and systemic thinking by putting themselves in the role of a social entrepreneur who must manage resources, not only reducing waste but also creating energy, employment, transport, housing and telecommunications in a clean, economic and sustainable way. Thus, we understood that it was useful for the processes of education for sustainability, especially in areas that are not specific to each university degree. For example, the primary education degree will focus specifically on SDG 4 (quality education), but with the use of the SG, they also worked on other SDGs related to the environment (SDG 7, climate action) or the economy (SDG 12, responsible production and consumption).

The results of this research can contribute both to the students who have participated in the learning activity, so that they are aware of the possible differences that may exist in their level of acquisition and training in sustainability development education (SDE) through SGs, and to the teaching staff and competent bodies in the university, so that they adapt their programs and methodologies to the use of SGs.

In summary, this research was configured as an exploratory study that opens the way for new research that reflects on how collaborative learning through an SG affects the level of knowledge of the SDGs and the perception of their importance. To transfer into practice this experience carried out in higher education students, it should be noted that it can be extrapolated and adapted to any educational stage, adapting both spaces and times, as well as taking into account the digital competence of each of the participants involved in the experiment.

The intention is to initiate a field of research that presents a significant deficit in the scientific literature, which is based on the number of investigations that analyze the incidence of collaborative learning through SGs to improve the knowledge of the SDGs. Although the size of the sample limits the possibility of generalizing the results, this study can serve as a starting point for new research on the topic analyzed.

Future research could consist of extending the sample to students with degrees in other areas. Therefore, it would be enriching for the literature to compare the obtained results in this paper with transversal professional skills needed to achieve the SDGs. 
Author Contributions: N.P.-M., leader of the research team "Simulator for the development of Social Competences" of the CBL call of UPVEHU 2019, has contributed as an academic specialist with experience in the use of the SG as a tool for education in sustainability in the field of Economics and Business degrees. J.C.-L. has contributed as an academic specialist with experience in active methodologies for sustainability and as the main responsible for the statistical analyses of this study. A.S.-I. has especially contributed to the design of the surveys and leading the learning sessions that are the object of this study in the classroom, as well as presenting previous versions of this article at international conferences. All authors have read and agreed to the published version of the manuscript.

Funding: We are grateful for the financial support received from Campus Bizia Lab programm -19Peña project and Specialized Group of Educational Innovation Business Professionalism UPV/EHU - HBT ADITUAK 2019/20: 117, both supported by University of the Basque Country (UPV/EHU).

Conflicts of Interest: The authors declare no conflict of interest.

\section{References}

1. United Nation. La Asamblea General Adopta la Agenda 2030 Para el Desarrollo Sostenible. Available online: https://www.un.org/sustainabledevelopment/es/2015/09/la-asamblea-general-adopta-la-agenda2030-para-el-desarrollo-sostenible/ (accessed on 17 June 2019).

2. UNESCO. La UNESCO y los Objetivos de Desarrollo Sostenible. Available online: https://es.unesco.org/sdgs (accessed on 17 June 2019).

3. SDG Compass. The Guide for Business Action on the SDGs. GRI, United Nations Global Compact. Available online: https://sdgcompass.org/wp-content/uploads/2015/12/019104_SDG_Compass_Guide_2015. pdf (accessed on 17 June 2019).

4. González Bravo, M.I. Responsabilidad social financiera. El papel fundamental de un sistema financiero sostenible. Rev. AECA 2019, 126, 26-28.

5. Spanish Parlament-Parlamento de España. Ley 11/2018, de 28 de Diciembre, por la que se Modifica el Código de Comercio, el Texto Refundido de la Ley de Sociedades de Capital Aprobado por el Real Decreto Legislativo 1/2010, de 2 de julio, y la Ley 22/2015, de 20 de Julio, de Auditoría de Cuentas, en Materia de Información no Financiera y Diversidad. Available online: https://www.boe.es/buscar/doc.php?id=BOE-A-2018-17989 (accessed on 14 May 2019).

6. Amaral, L.P.; Martins, N. Quest for a sustainable university: A review. Int. J. Sustain. Higher Educ. 2015, 16, 155-172. [CrossRef]

7. Albareda-Tiana, S.; Azcárate Goded, P.; Muñoz-Rodríguez, J.M.; Valderrama-Hernández, R.; Ruiz-Morales, J. Evaluar competencias en sostenibilidad en los grados y posgrados de educación: Propuesta de un instrumento. Enseñ. Cienc. 2019, 37, 11-29. [CrossRef]

8. Combes, B. Red Internacional de Organizaciones de Educación para el Desarrollo Sostenible. Prólogo. Rev. Cátedra UNESCO Desarro. Sosten. UPV/EHU 2018, 8, 11-13.

9. Prado, A.M.; Arce, R.; Lopez, L.E.; García, J. Simulations Versus Case Studies: Effectively Teaching the Premises of Sustainable Development in the Classroom. J. Bus. Ethics 2020, 161, 303-327. [CrossRef]

10. Miler, G.E. The assessment of clinical skilles/competence/performance. Acad. Med. 1990, 65, 63-67. [CrossRef] [PubMed]

11. Pozo-Sánchez, S.; López-Belmonte, J.; Fuentes-Cabrera, A.; López-Núñez, J.A. Gamification as a Methodological Complement to Flipped Learning-An Incident Factor in Learning Improvement. Multimodal Technol. Interact. 2020, 4, 12. [CrossRef]

12. Espinosa, R.S.; Contreras Eguia, J.L. Gamificación en Aulas Universitarias; Institut de la Comunicació: Bellaterra, Spain, 2016.

13. EuropaPress. El $92 \%$ de los Profesores Españoles Considera que la Gamificación en los Centros Educativos es Insuficiente, EuropaPress Comunicados, 11 de Febrero. Available online: https://www.europapress.es/comunicados/sociedad-00909/noticia-comunicado-92-profesores-espanolesconsidera-gamificacion-centros-educativos-insuficiente-20190211114902.html (accessed on 18 March 2019).

14. Pozo-Sánchez, S.; López-Belmonte, J.; Fuentes-Cabrera, A.; Moreno-Guerrero, A.J. Incidencia de la retro-innovación en educación superior. Radio y televisión como herramientas complementarias en el uso del modelo de enseñanza conocido como aprendizaje invertido. Formac. Univ. 2020, 13, 139-146. [CrossRef] 
15. Katsaliaki, K.; Muysafee, N. Edutainement for sustainable development: A survey of games in the field. Simul. Gaming 2015, 46, 647-672. [CrossRef]

16. Ouariachi, T.; Olvera-Lobo, M.D.; Gutiérrez-Pérez, J. Gaming Climate Change: Assessing Online Climate Change Games Targeting Youth Produced in Spanish. Procedia-Soc. Behav. Sci. 2017, 237, 1053-1060. [CrossRef]

17. Ouariachi, T.; Olvera-Lobo, M.D.; Gutiérrez-Pérez, J. Can serious games help to mitigate climate change? Exploring their influence on Spanish and American teenagers' attitudes. PsycoEcology 2018, 9, 365-395. [CrossRef]

18. Rojo, T.; Dudu, S. Los videojuegos en la implementación de políticas de mitigación del cambio climático. Ámbitos 2017, 37, 1-25. [CrossRef]

19. Calabor, M.S.; Araceli Moya, S.; Mora, S. Adquisición de competencias a través de juegos serios en el área contable: Un análisis empírico. Rev. Contab.-Span. Account. Rev. 2018, 21,38-47. [CrossRef]

20. Ibarra-Berastegi, G.; García-Arriba, R. Using open software in engineering studies: A sustainable tool. In Proceedings of the IEEE Global Engineering Education Conference, Athens, Greece, 25-27 April 2017. [CrossRef]

21. Area, M.; Hernández, V.; Sosa, J.J. Modelos de integración didáctica de las TIC en el aula. Comunicar 2016, 24, 79-87. [CrossRef]

22. Garrote, D.; Arenas, J.A.; Jiménez-Fernández, S. ICT as tools for the development of intercultural competence. EDMETIC 2018, 7, 166-183. [CrossRef]

23. Li, S.; Yamaguchi, S.; Sukhbaatar, J.; Takada, J. The Influence of Teachers' Professional Development Activities on the Factors Promoting ICT Integration in Primary Schools in Mongolia. Educ. Sci. 2019, 9, 78. [CrossRef]

24. Petratos, P.; Damaskou, E. Management strategies for sustainability education, planning, design, energy conservation in California higher education. Int. J. Sustain. Higher Educ. 2015, 16, 576-603. [CrossRef]

25. Caamaño, A. ¿Cómo introducir la indagación en el aula? Los trabajos prácticos indagativos. Didáct. Cienc. Exp. 2012, 70, 83-91.

26. Mulà, I.; Tilbury, D.; Ryan, A.; Mader, M.; Dlouhá, J.; Mader, C.; Benayas, J.; Dloughý, J.; Alba, D. Catalysing change in higher education for sustainable development: A review of professional development initiatives for university educators. Int. J. Sustain. Higher Educ. 2017, 18, 798-820. [CrossRef]

27. Gil-Pérez, D.; Vilches, A. La formación del profesorado de ciencias de secundaria... y de universidad. La necesaria superación de algunos mitos bloqueadores. Educ. Quím. 2004, 15, 43-51.

28. Vilches, A.; Gil-Pérez, D. La educación para la sostenibilidad en la Universidad: El reto de la formación del profesorado. Profr. Rev. Curric. Form. Profr. 2012, 15, 25-43. [CrossRef]

29. UPV/EHU. La UPV/EHU Introduce la Tercera Casilla en el Apartado de Sexo de Todos sus Formularios. Available online: https://www.ehu.eus/es/content/-/asset_publisher/W6wn/content/n_20171103-terceracasilla-consejo-gv (accessed on 20 June 2019).

30. Porto, B. Feminización y masculinización en los estudios de maestro y educación física en Galicia. Rev. Investig. Educ. 2009, 6, 50-57.

31. Canals, R.M.; Durán, M.; Múgica, L.; San Emeterio, L. Formando futuras investigadoras: Introduciendo la ciencia ecológica y ambiental al mundo escolar. Ecosistemas 2019, 28, 116-119. [CrossRef]

32. García González, E. Análisis de la Presencia de los Principios de Sostenibilidad en Propuestas Metodológicas Universitarias: Estudio de Propuestas Concretas en la Universidad de Cádiz. Ph.D. Thesis, Universidad de Cádiz, Cadiz, Spain, 24 April 2016. Available online: http://hdl.handle.net/10498/18346 (accessed on 24 June 2019).

(C) 2020 by the authors. Licensee MDPI, Basel, Switzerland. This article is an open access article distributed under the terms and conditions of the Creative Commons Attribution (CC BY) license (http://creativecommons.org/licenses/by/4.0/). 